\title{
НАЦИОНАЛЬНЫЙ ПРОЕКТ «ПРОИЗВОДИТЕЛЬНОСТЬ ТРУДА И ПОДДЕРЖКА ЗАНЯТОСТИ НАСЕЛЕНИЯ» В СИСТЕМЕ ОБЕСПЕЧЕНИЯ УСТОЙЧИВОГО ЭКОНОМИЧЕСКОГО РАЗВИТИЯ
}

В статье проведен анализ низкой производительности труда в стране, выделен ряд проблем, препятствуюиих росту производтельности труда и предложсны направления ее повыиения. Установлено, что повышение производительности труда является важнейшим фактором, обеспечиваюищм рост национальной и региональной экономики.

Одним из приоритетных направлений в этой области на ближайцие годы (2019-2024 г2.) должна стать реализация национального проекта по повыиению производительности труда. Ключевой целью данного проекта является стимулирование интереса со стороны региональных и федеральных органов власти, предприятий и обеспечение роста производительности труда на предприятиях базовых несырьевых отраслей. Национальный проект будет включать в себя меры, стимулирующие предприятия к повыиению производительности труда, меры по снижению административно-правовых ограничений, созданию системы подготовки управленческих кадров и т. д. Важсиым звеном в данном проекте является разработка и реализация программ производительности труда в субъектах Российской Федерации и на предприятиях регионов.

Ключевые слова: экономический рост, производительность труда, инвестиции, программа, национальный проект.

\section{Svetlana Poluektova \\ NATIONAL PROJECT «LABOR PRODUCTIVITY AND SUPPORT OF EMPLOYMENT» IN THE SYSTEM OF SUSTAINABLE ECONOMIC DEVELOPMENT}

The article analyzes the low level of labor productivity in the country, identifies a number of problems that constrain the growth of labor productivity, as well as the directions of its increase. It is established that the increase in labor productivity is the most important factor that ensures the growth of the national and regional economy.

One of the priorities in this area for coming years (2019-2024) should be the implementation of a national project of labor productivity growth. The key objective of this project is to stimulate interest on the part of regional and federal authorities, enterprises and to ensure the growth of labor productivity in enterprises of basic non-resource industries. The national project will include measures to encourage enterprises to increase productivity, reduce administrative and legal restrictions, create a system of management training, etc. An important link in this project is the development and implementation of labor productivity programs in the regions of the Russian Federation and enterprises of the regions.

Key words: economic growth, labor productivity, investments, program, national project.

Bвedeниe / Introduction. Переход страны к устойчивому развитию невозможен без направления вектора отдельных элементов государства - субъектов Федерации - в сторону реализации целей устойчивого развития.

В последние десятилетия в России проблема обеспечения устойчивого развития региональных социально-экономических систем представляет повышенный интерес. Это связано, во-первых, с неустойчивым типом развития большинства российских социально-экономических систем 
регионального уровня, характеризующимся отсутствием сбалансированности воспроизводства социально-экономического, ресурсного, экологического потенциала разбалансированностью воспроизводственных механизмов. Во-вторых, с утверждением Указов Президента Российской Федерации, определяющих ключевыми целями долгосрочной экономической политики увеличение экономического роста и обеспечение его устойчивости, достижение технологического лидерства российской экономики, что задает вектор для роста экономического потенциала страны.

Несмотря на многие исследования по проблемам устойчивого развития социально-экономических систем (труды отечественных экономистов, таких как: Ю. М. Ипатова, В. И. Гурмана, В. И. Данилова-Данильяна, И. И. Думовой, Г. Б. Клейнера, В. М. Ходачека, В. Е. Селиверстова, В. К. Сенчагова), недостаточная комплексная проработка инструментария в рамках данного направления предопределила выбор темы исследования.

В сложившихся современных экономических условиях повышение производительности труда и эффективности использования всех производственных ресурсов становится одним из ведущих факторов роста экономики и инструментов обеспечения устойчивого развития.

Материалы и методы / Materials and methods. На основе анализа материалов официальной статистики проанализирована динамика индекса производительности труда, основного индикатора производительности труда. Изучены официальные документы президиума Совета при Президенте Российской Федерации по стратегическому развитию и национальным проектам в рамках вопроса повышения производительности труда. Для достижения задач исследования были применены следующие методы системного подхода, анализа и синтеза, статистический метод. Для наглядности выявленные экономические зависимости были представлены при помощи метода графических изображений.

Индекс производительности труда по экономике региона является одним из интегральных показателей экономической эффективности региона, который, согласно методике Росстата, равен частному от деления индекса физического объема валового регионального продукта (далее ВРП) на индекс изменения совокупных затрат труда в эквиваленте полной занятости. Индекс производительности труда - это показатель качества рабочей силы, капитала, организации труда и уровня используемых технологий.

В настоящее время в России мониторинг достижения целевого индикатора роста производительности труда в соответствии с Указом Президента РФ от 7 мая 2012 г. № 596 «О долгосрочной государственной экономической политике» проводится с использованием показателя «Индекс производительности труда относительно уровня 2011 года» [1]. Согласно официальным данным Росстата, по данному показателю Указа за последние годы в России наблюдается отрицательная динамика (105,6 \% - 2013 г., 106,3 \% - 2014 г., 104,3 \% - 2015 г., $104 \%$ - 2016 г.) [2].

Определяющим фактором развития экономики и повышения производительности труда является эффективная инвестиционная политика. Показатель прироста производительности труда важнейший показатель инвестиционной деятельности. В современных условиях хозяйствования именно показатель производительности труда должен быть использован при формировании и реализации инвестиционной политики [3]. Реализация инвестиционной политики должна быть направлена на создание комфортных условий для развития предпринимательства, активацию инвестиционной деятельности путем привлечения инвестиций и потенциальных инвесторов, путем повышения их статуса и обеспечения прав собственности.

В январе - декабре 2017 года динамика инвестиций в основной капитал по Российской Федерации составила 104,8 \%, по ЦФО 108,4\% к соответствуюшему периоду предыдушего года.

Недостаточный уровень производительности труда - значимая проблема, препятствующая конкурентоспособности страны. Для преодоления разрыва в производительности, Россия должна стать «лидером» по привлечению масштабных частных прямых инвестиций в создание новых 
рабочих мест в отраслях с высоким уровнем производительности. Государство должно пересмотреть инвестиционные приоритеты на ближайшие 2-3 года, сфокусировавшись на интенсивной диверсификации экономики и повышении уровня производительности [4].

Вопрос по повышению уровня производительности труда в стране находится под пристальным рассмотрением уже не первый год. Он решается прежде всего путем стимулирования обновления средств труда на предприятиях, а также проведения управленческих мероприятий.

По данным Организации экономического сотрудничества и развития (далее - ОЭСР), в 2017 году производительность труда в России (показатель валового внутреннего продукта в расчете на час отработанного времени) была ниже в два раза, чем в других странах ОЭСР (см. рис.1). Производительность труда в данном случае представляет собой частное от деления выручки на среднесписочную численность персонала.

\section{Производительность труда в странах ОЭСР и в России \\ (долл.СШАна 1 час отработанноговремени)}

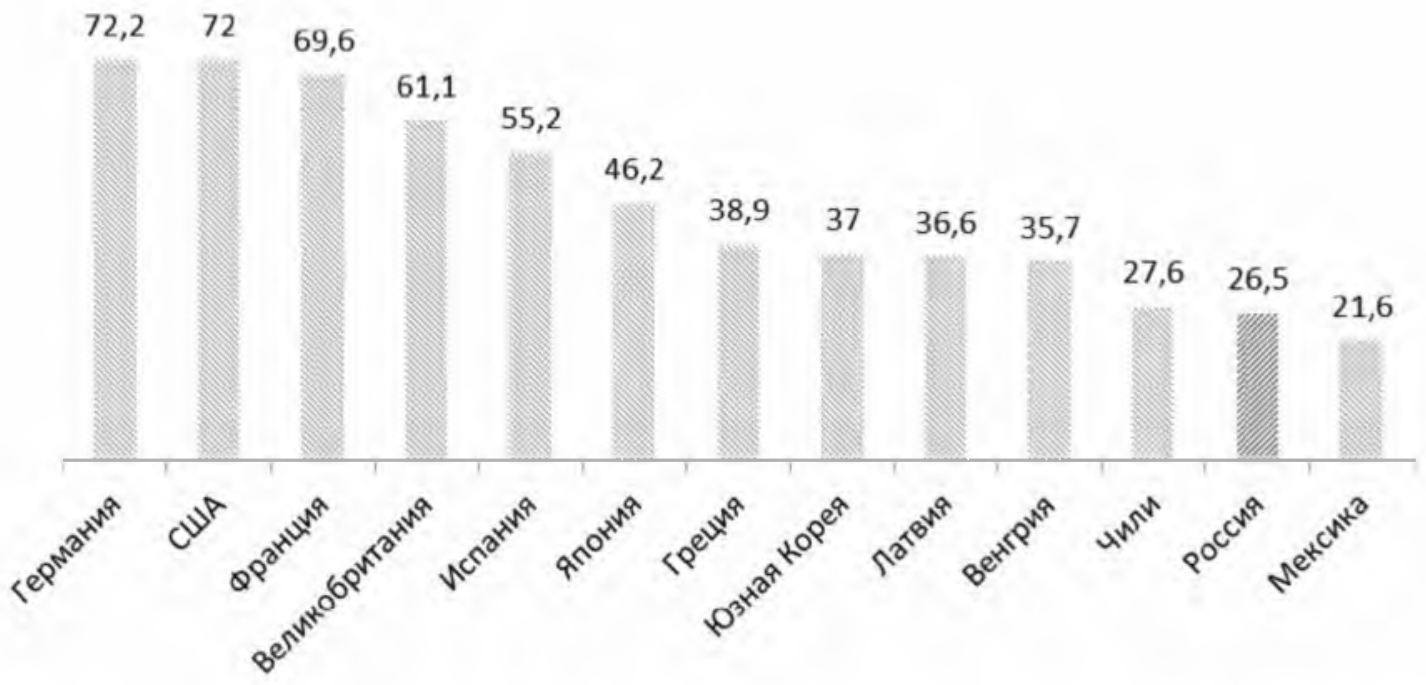

Рис. 1. Производительность труда по данным Организации экономического сотрудничества и развития в 2017 году

Устойчивый экономический рост, развитие экономики, возможность выполнения социальных гарантий во многом определяются уровнем производительности в стране.

Всероссийский проект по повышению производительности труда в стране должен обеспечить рост производительности.

В декабре 2018 года президиумом Совета при Президенте РФ был утвержден паспорт национального проекта по производительности труда и поддержке занятости.

В рамках реализации национального проекта поставлены следующие цели:

1. Обеспечить рост производительности труда не ниже 5\% в год к 2024 г. (на средних и крупных предприятиях базовых несырьевых отраслей экономики);

2. Ежегодное привлечение субъектов РФ к участию в программе $>10,85$ субъектов к 2024 г;

3. Средних и крупных предприятий базовых несырьевых отраслей экономики $>10000$ к 2024 г.

Национальный проект включает в свою структуру три федеральных проекта и региональные проекты субъектов Российской Федерации (см. рис. 2) [5]. 


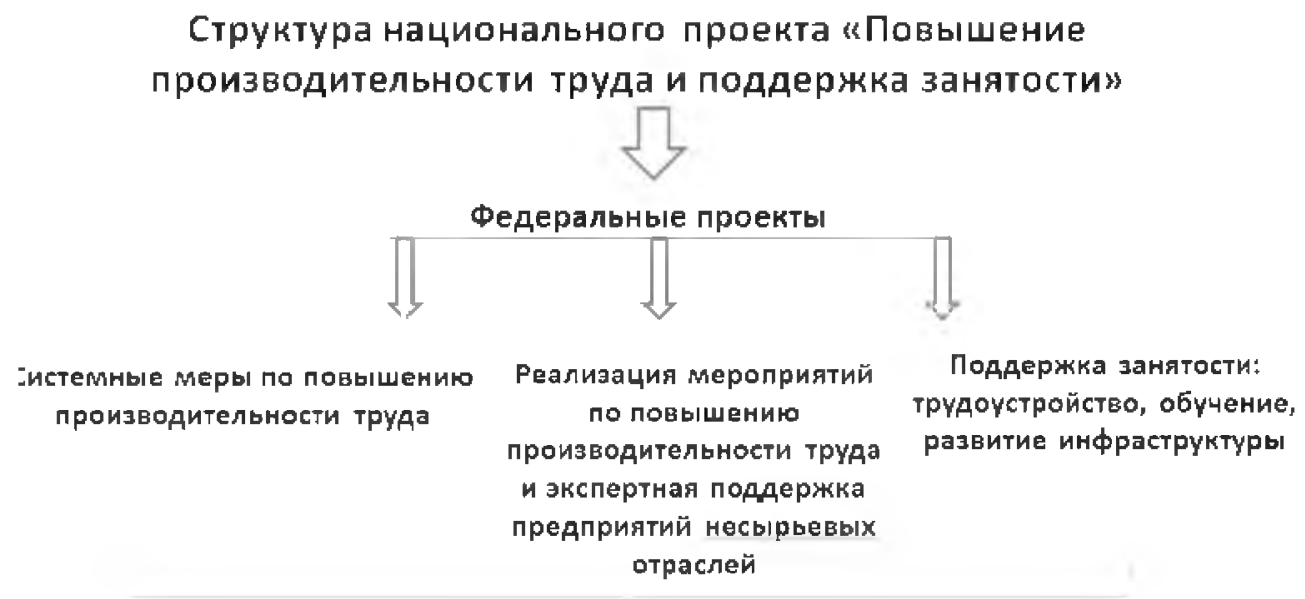

Региональные проекты субъектов РФ

Рис. 2. Структура национального проекта «Повьшение производительности труда и поддержка занятости»

Безусловно, основным звеном национального проекта являются программы субъектов Российской Федерации. Проект будет основываться на разработке и реализации программ производительности труда на мезо- и микроуровнях экономики (регионов и предприятий) с использованием опыта «первооткрывателей» (пилотных регионов). Проект будет включать пакет мер по государственной поддержке предприятий, снижению административных барьеров, программы по переобучению работников, создание центров компетенций в сфере производительности труда [6].

Одним из направлений проекта станет поддержка занятости и повышение эффективности рынка труда. Главным источником экономического развития региона становятся инвестиции в человека, в его квалификацию, в повышение производительности труда и обновление производства, создание эффективных высокооплачиваемых рабочих мест [7].

За последние 12 лет численность населения в трудоспособном возрасте в России сократилась почти на $9 \%$ и, по данным Росстата, в 2018 году составила 82,3 млн человек. В условиях демографических угроз и сокращения рабочей силы численность занятого населения сократится с 72,1 млн человек в 2016 году до 71,7 млн человек в 2020 году [8].

Негативную демографическую ситуацию на рынке труда будет смягчать рост работающих лиц старше пенсионного возраста. Их удельный вес в составе трудовых ресурсов увеличится с 2016 по 2020 гг. почти на $1 \%(0,6 \%)$.

Потенциал создания новых рабочих мест связан в основном с экономическим ростом и формированием необходимых условий для начала реализации новых проектов (в том числе проекта по производительности труда).

Проблема производительности труда имеет многоаспектный характер, и для ее решения требуется комплексный подход для устранения не одного, а сразу нескольких барьеров.

Ключевыми барьерами на пути повышения производительности труда и обеспечения высокого уровня занятости населения являются:

в части роста производительности труда:

- высокий уровень износа основных средств;

- низкий уровень использования среднегодовой производственной мощности предприятий; 
- д дефицит производственных мощностей, препятствующий переработке профицита имеющихся ресурсов и увеличению выпуска готовой продукции;

- низкий уровень интеграции науки и бизнеса. Недостаточное количество высококвалифицированных работников, связанное с низкой квалификацией существующего персонала и ротацией кадров пенсионного возраста. Наиболее острый дефицит узкоспециализированных специалистов инженерно-технического персонала;

- низкий уровень инновационной активности предприятий;

- нехватка собственных денежных средств у предприятий делает невозможным процесс нововведений [9];

- в части обеспечения высокого уровня занятости населения:

- дефицит квалифицированных кадров, инженерно-технического персонала [10];

- старение и отток кадров;

- $\quad$ высокая доля ручного труда.

Pезультаты и обсужсдение /Results and discussion. На основании изложенного можно определить ряд направлений по повышению уровня производительности труда и поддержки занятости:

1. Разработка и реализация на местах (субъектах и предприятиях данных субъектов) комплекса мер по повышению производительности труда с последующим масштабированием полученной практики на другие субъекты Российской Федерации и иные заинтересованные предприятия регионов, включающего:

- стимулирование эффективности функционирования производственных систем;

- повышение производственной активности;

- стимулирование процесса цифровизации;

- совершенствование механизмов ускорения трансфера инновационных технологий.

2. Наряду с этим требуется модернизация системы кадрового менеджмента - проведение в субъектах Российской Федерации аудита имеющейся системы занятости с учетом особенностей отраслей и предприятий регионов. По итогам проведения аудита следует разработать и реализовать ряд мер, способных:

- обеспечить рост эффективности функционирования системы занятости и повышение доступности и качества услуг по трудоустройству,

- решить проблемы занятости в каждом конкретном субъъекте РФ,

- стимулировать создание новых рабочих мест,

- установить равновесие спроса и предложения рабочей силы,

- наладить сотрудничество между службами занятости, работодателями, образовательными организациями и другими участниками рынка труда.

3. Формирование инфраструктуры, необходимой для исполнения запланированных мероприятий по повышению управленческих квалификаций руководителей и специалистов всех уровней власти.

4. Создание региональных центров компетенций в сфере производительности труда, которые будут содействовать внедрению типовых решений для обеспечения устойчивого роста производительности труда и распространению инноваций в организации производственных и управленческих процессов.

Заключение/ Conclusion. Обоснована ключевая роль повышения производительности труда как важнейшего фактора в обеспечении устойчивого развития, способствующего данному развитию и включающего необходимость разработки региональных программ производительности труда.

Рассмотрены основные предпосылки для разработки всероссийского проекта в сфере повышения производительности труда и ключевые составляющие, показатели данного проекта.

Определены основные барьеры, препятствующие росту производительности, обеспечению высокого уровня занятости населения и предложен ряд направлений, нацеленных на устранение существующих барьеров. 
В заключение хотелось бы отметить, что реализация национального проекта в сфере производительности и предлагаемого уровня направлений, на наш взгляд, будет содействовать экономическому росту, росту производительности и в целом конкурентоспособности страны.

Практическая ценность проведенного исследования заключается в том, что его результаты могут быть использованы при разработке региональных программ повышения производительности труда и поддержки занятости.

\section{ЛИТЕРАТУРА И ИНТЕРНЕТ-РЕСУРСЫ}

1. О долгосрочной государственной экономической политике: Указ Президента Российской Федерации от 7 мая 2012 г. № 596 [Электронный ресурс]. Доступ из справ.-правовой системы «КонсультантПлюс регион» (дата обращения: 10.01.2019).

2. Федеральная служб̄а государственной статистики [Электронный pecypc]. URL: http://www.gks.ru (дата обращения: 04.02.2019)

3. Бездудный Ф. Ф., Друзгальская М. Н., Любименко А. И. Рост производительности труда как одна из форм инвестиций в повышение эффективности функционирования предприятий // ИННОВАЦИИ. СПб: Изд-во ООО «Трансфер-Инновации». 2008. № 11. С. 88-90.

4. Идрисов А. Производительность труда как ключевой фактор конкурентоспособности российской экономики. URL: http: //strategy.ru/research/3/ (дата обращения: 28.02.2019)

5. Горчакова С. В. Структура Национального проекта «Производительность труда и поддержка занятости» [Электронный ресурc] URL: http://www.yarregion.ru/depts/der/Documents/Суханова\%20 Елена\%20Владимировна/Производительность\%20труда/Структура\%20нацпроекта.pdf (дата обращения: 27.02.2019)

6. Паспорт приоритетной программы «Повышение производительности труда и поддержка занятости» [Электронный ресурс]. Доступ из справ.-правовой системы «КонсультантПлюс регион» (дата обращения: 16.11.2018)

7. Лаптев Н. В. Создание и модернизация рабочих мест как эффективная стратегия развития рынка труда Ульяновской области // Спрос и предложение на рынке труда и рынке образовательных услуг в регионах России: сборник докладов по материалам X Всероссийской научно-практической интернет-конференции / под редакцией В. А. Гуртова. Книга 1. 2013. 325 с.

8. Информация Министерства труда и социальной защиты РФ от 27 ноября 2017 г. «Прогноз баланса трудовых ресурсов на 2018-2020 годы» [Электронный pecypc]. URL: http://www.garant.ru/products/ ipo/prime/doc/71725490/ (дата обращения: 15.01.2019)

9. Полина С. В. Проблемы повышения производительности труда в экономике региона // Вопросы территориального развития. 2017. №.1 (36) . С. 7

10. Варшавский А. Е., Кочеткова Е. В. Проблемы дефицита инженерно-технических кадров // Экономический анализ: теория и практика. 2015. № 32. С. 2-16.

\section{REFERENCES AND INTERNET RESOURCES}

1. «O dolgosrochnoj gosudarstvennoj jekonomicheskoj politike: Ukaz Prezidenta Rossijskoj Federacii ot 7 maja 2012 g. No. 596 [Jelektronnyj resurs]. Dostup iz sprav.-pravovoj sistemy «Konsul'tantPljus region» (data obrashhenija: 10.01.2019).

2. Federal'naja sluzhba gosudarstvennoj statistiki [Jelektronnyj resurs]. URL: http://www.gks.ru (data obrashhenija: 04.02.2019)

3. Bezdudnyj F. F., Druzgal'skaja M. N., Ljubimenko A. I. Rost proizvoditel'nosti truda kak odna iz form investicij v povyshenie jeffektivnosti funkcionirovanija predprijatij (Labor productivity growth as a form of investment in improving the efficiency of enterprises) // Zhurnal INNOVACII. SPb.: Izd-vo OOO «Transfer-Innovacii». 2008. No.11. S. 88-90.

4. Idrisov A. Proizvoditel'nost' truda kak kljuchevoj faktor konkurentosposobnosti rossijskoj jekonomiki (Labor productivity as a key factor of competitiveness of the Russian economy). URL: http: //strategy.ru/ research/3/ (data obrashhenija: 28.02.2019) 
5. Gorchakova S. V. Struktura Nacional'nogo proekta «Proizvoditel'nost' truda i podderzhka zanjatosti», [Jelektronnyj resurs]. URL: http://www.yarregion.ru/depts/der/Documents/Suhanova\%20Elena\%20 Vladimirovna/Proizvoditel'nost \%20truda/Struktura\%20nacproekta.pdf (data obrashhenija: 27.02.2019)

6. Pasport prioritetnoj programmy «Povyshenie proizvoditel'nosti truda i podderzhka zanjatosti» [Jelektronnyj resurs]. Dostup iz sprav.-pravovoj sistemy «Konsul'tantPljus region» (data obrashhenija: 16.11.2018)

7. Laptev N. V. Sozdanie i modemizacija rabochih mest kak jeffektivnaja strategija razvitija rynka truda ul'janovskoj oblasti (Creation and modernization of jobs as an effective strategy for the development of the labor market of the Ulyanovsk region) // Spros i predlozhenie na rynke truda i rynke obrazovatel'nyh uslug v regionah Rossii: sbornik dokladov po materialam X Vserossijskoj nauchno-prakticheskoj internetkonferencii / pod redakciej V. A. Gurtova. Kniga 1.2013.325 s.

8. Informacija Ministerstva truda i social'noj zashhity RF of 27 nojabrja 2017 g. «Prognoz balansa trudovyh resursov na 2018-2020 gody» [Jelektronnyj resurs]. URL: http://www.garant.ru/products/ipo/prime/ doc/71725490/. Dostup iz sprav.-pravovoj sistemy «Garant» (data obrashhenija: 15.01.2019)

9. Polina S. V. Problemy povyshenija proizvoditel'nosti truda v jekonomike regiona (Problems of increasing labor productivity in the region's economy) // Voprosy territorial'nogo razvitija. 2017. No.1 (36). S. 7.

10. Varshavskij A. E., Kochetkova E. V. Problemy deficita inzhenerno-tehnicheskih kadrov (Problems of shortage of engineering and technical personnel) // Jekonomicheskij analiz: teorija i praktika. 2015. No. 32. S. 2-16.

\section{СВЕДЕНИЯ ОБ АВТОРЕ}

Полуэктова Светлана Леонидовна, аспирант кафедры политической экономии и современных бизнес-процессов, Тамбовский государственный университет имени Г. Р. Державина, Россия. E-mail: poluektovasweta@mail.ru

\section{INFORMATION ABOUT AUTHOR}

Svetlana Poluektova, post-graduate student, Department of political economy and modern business processes, Tambov State University named after G. R. Derzhavin, Russia. E-mail: poluektovasweta@mail.ru 